[2] Braun et al. Effect of secukinumab on clinical and radiographic outcomes in ankylosing spondylitis: 2-year results from the randomised phase III MEASURE 1 study. Ann Rheum Dis. 2017 Jun;76(6):1070-1077

Disclosure of Interests: None declared

DOI: 10.1136/annrheumdis-2020-eular.4969

\section{FRI0281 NON-STEROIDAL ANTI-INFLAMMATORY DRUGS IN PATIENTS WITH STABLE ANKYLOSING SPONDYLITIS RECEIVING TUMOR NECROSIS FACTOR INHIBITOR: CONTINUED VS WITHDRAWN}

O. C. Kwon ${ }^{1}$, J. H. Park', M. C. Park'. ${ }^{1}$ Yonsei University College of Medicine, Division of Rheumatology, Department of Internal Medicine, Seoul, Korea, Rep. of (South Korea)

Background: A recent recommendation from the American College of Rheumatology/Spondylitis Association of America/Spondyloarthritis Research and Treatment Network (ACR/SAA/SPARTAN) suggests withdrawing non-steroidal anti-inflammatory drugs (NSAIDs) in patients with stable ankylosing spondylitis (AS) receiving tumor necrosis factor inhibitor (TNFi) and NSAIDs. ${ }^{1}$ However, the level of evidence for this statement is very low with lack of evidence supporting this recommendation. No studies have directly compared stable AS patients receiving TNFi with NSAIDs, and those receiving TNFi without NSAIDs.

Objectives: To compare the disease activity in stable AS patients receiving TNFi, according to the use of NSAIDs.

Methods: In total, 189 patients with stable AS receiving TNFi were included. Patients were classified into NSAID withdrawn group $(n=48)$ and NSAID continued group ( $n=141)$, according to the use of NSAIDs. Erythrocyte sedimentation rate (ESR) and C-reactive protein (CRP) were measured every 3 months, and Bath ankylosing spondylitis disease activity index (BASDAI) was measured every 6 months as parameters to evaluate disease activity. ESR, CRP, and BASDAI at each time point, and time-averaged values of each parameter during the observation period of one-year were compared between the two groups. Repeated-measure ANOVA was performed to compare changes in disease activity parameters during the observation period between the two groups.

Table. Disease activity measures during observation period

\begin{tabular}{|c|c|c|c|}
\hline & $\begin{array}{l}\text { NSAID } \\
\text { withdrawn } \\
(\mathrm{N}=48)\end{array}$ & $\begin{array}{c}\text { NSAID } \\
\text { continued } \\
(\mathrm{N}=141)\end{array}$ & $P$ value \\
\hline \multicolumn{4}{|l|}{ At 3 months } \\
\hline ESR $(\mathrm{mm} / \mathrm{hr})$, median (IQR) & $5.0(2.0-14.0)$ & $7.0(2.0-15.0)$ & 0.712 \\
\hline CRP (mg/L), median (IQR) & $0.5(0.2-1.5)$ & $0.8(0.3-1.8)$ & 0.613 \\
\hline \multicolumn{4}{|l|}{ At 6 months } \\
\hline ESR (mm/hr), median (IQR) & $5.0(2.0-15.0)$ & $7.0(2.0-15.0)$ & 0.278 \\
\hline CRP (mg/L), median (IQR) & $0.6(0.3-1.8)$ & $0.8(0.3-2.1)$ & 0.335 \\
\hline BASDAI, mean \pm SD & $2.019 \pm 0.569$ & $2.226 \pm 1.028$ & 0.187 \\
\hline \multicolumn{4}{|l|}{ At 9 months } \\
\hline ESR (mm/hr), median (IQR) & $4.5(2.0-13.8)$ & $7.0(2.8-17.0)$ & 0.261 \\
\hline $\mathrm{CRP}(\mathrm{mg} / \mathrm{L})$, median (IQR) & $0.5(0.3-1.6)$ & $0.8(0.3-2.2)$ & 0.129 \\
\hline \multicolumn{4}{|l|}{ At 12 months } \\
\hline ESR (mm/hr), median (IQR) & $6.0(2.0-13.0)$ & $9.0(3.0-19.0)$ & 0.050 \\
\hline CRP (mg/L), median (IQR) & $0.6(0.3-2.1)$ & $1.0(0.4-3.1)$ & 0.151 \\
\hline BASDAI, mean \pm SD & $2.168 \pm 1.066$ & $2.197 \pm 1.002$ & 0.867 \\
\hline \multicolumn{4}{|l|}{ Time-averaged values } \\
\hline ESR $(\mathrm{mm} / \mathrm{hr})$, median (IQR) & $5.3(2.6-15.2)$ & $8.4(3.8-14.7)$ & 0.096 \\
\hline CRP (mg/L), median (IQR) & $0.8(0.4-1.8)$ & $1.1(0.5-2.9)$ & 0.136 \\
\hline BASDAI, mean \pm SD & $2.137 \pm 0.557$ & $2.227 \pm 0.706$ & 0.421 \\
\hline
\end{tabular}

Abbreviations: NSAIDs, non-steroidal anti-inflammatory drugs; ESR, erythrocyte sedimentation rate; CRP, C-reactive protein; BASDAI, Bath ankylosing spondylitis disease activity index.

Results: The level of ESR, CRP, and BASDAI at baseline and during the observation period did not differ between the two groups. The time-averaged values of ESR $(p=0.096)$, CRP $(p=0.136)$, and BASDAI $(p=0.421)$, and changes of ESR $(p=0.101), \operatorname{CRP}(p=0.714)$, and BASDAI $(p=0.613)$ during the observation period were not significantly different between the two groups.

Conclusion: The continued use of NSAIDs in patients with stable AS receiving TNFi had no additional benefit in controlling the disease activity, as compared to patients who withdrew NSAIDs. Considering the risk of toxicity of long-term NSAID use, withdrawal of NSAIDs in stable AS patients receiving TNFi may be preferable.

References:

[1] Ward MM, Deodhar A, Gensler LS, et al. 2019 Update of the American College of Rheumatology/Spondylitis Association of America/Spondyloarthritis Research and Treatment Network Recommendations for the Treatment of Ankylosing Spondylitis and Nonradiographic Axial Spondyloarthritis. Arthritis Rheumatol 2019;71:1599-613 doi: 10.1002/art.41042.
Acknowledgments: None.

Disclosure of Interests: None declared

DOI: 10.1136/annrheumdis-2020-eular.4066

\begin{tabular}{|l|l}
\hline FRI0282 & CONVENTIONAL DISEASE-MODIFYING \\
ANTIRHEUMATIC DRUGS THERAPY HAS NO \\
EFFICACY IN SLOWING SPINAL RADIOGRAPHIC \\
PROGRESSION IN ANKYLOSING SPONDYLITIS: \\
RESULTS FROM 18-YEAR LONGITUDINAL DATA
\end{tabular}

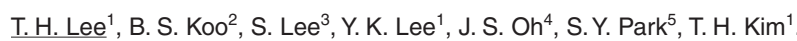
${ }^{1}$ Hanyang University Hospital for Rheumatic Diseases, Department of Rheumatology, Seoul, Korea, Rep. of (South Korea); '2 Inje University Seoul Paik Hospital, Inje University College of Medicine, Department of Internal Medicine, Seoul, Korea, Rep. of (South Korea); ${ }^{3}$ Hanyang University Hospital, Department of Radiology, Seoul, Korea, Rep. of (South Korea); ${ }^{4}$ Asan Medical Center, University of Ulsan College of Medicine, Department of Biomedical informatics, Seoul, Korea, Rep. of (South Korea); ${ }^{5}$ Asan Medical Center, University of Ulsan College of Medicine, Department of Clinical Epidemiology and Biostatistics, Seoul, Korea, Rep. of (South Korea)

Background: In the treatment of ankylosing spondylitis (AS), conventional disease-modifying antirheumatic drugs (cDMARDs) are generally recommended only in patients with peripheral arthritis. However in daily clinical practice, sulfasalazine (SSZ) and methotrexate (MTX) have still been considered on the basis of their anti-inflammatory effect when non-steroidal anti-inflammatory drugs (NSAIDs) are not available and when it is difficult to start tumor necrosis factor (TNF) inhibitors. Nonetheless there is few data about the impact of the cDMARDs on the prognosis of spinal progression.

Objectives: The aim of this study was to investigate the effectiveness of SSZ and MTX on the spinal radiographic progression in patients with AS.

Table 1. Association of clinical covariates and DMARD intervals with the rate of mSASSS change

\begin{tabular}{|c|c|c|c|c|}
\hline \multirow[t]{3}{*}{ Variable } & \multicolumn{4}{|c|}{ Multivariate analysis } \\
\hline & \multicolumn{2}{|l|}{ Model 1} & \multicolumn{2}{|l|}{ Model 2} \\
\hline & $\beta(95 \% \mathrm{Cl})$ & $\mathbf{p}$ & $\beta(95 \% \mathrm{Cl})$ & $p$ \\
\hline On-DMARD intervals & $-0.081(-0.276$ to 0.115$)$ & 0.418 & & \\
\hline On-SSZ intervals & & & $-0.001(-0.211$ to 0.189$)$ & 0.913 \\
\hline On-MTX intervals & & & $-0.180(-0.439$ to 0.078$)$ & 0.172 \\
\hline Sex (female) & $-0.449(-0.782$ to -0.117$)$ & 0.008 & $-0.440(-0.775$ to -0.105$)$ & 0.010 \\
\hline Age & $0.012(-0.001$ to 0.026$)$ & 0.061 & $0.012(-0.001$ to 0.025$)$ & 0.076 \\
\hline Eye involvement & $0.572(0.264$ to 0.880$)$ & $<0.001$ & $0.577(0.268$ to 0.886$)$ & $<0.001$ \\
\hline $\begin{array}{l}\text { Peripheral joint } \\
\text { involvement }\end{array}$ & $-0.508(-0.810$ to -0.206$)$ & 0.001 & $-0.513(-0.817$ to -0.210$)$ & 0.001 \\
\hline HLA-B27 positivity & $\dagger$ & & $\dagger$ & \\
\hline NSAIDs & $\dagger$ & & $\dagger$ & \\
\hline Glucocorticoids & $\dagger$ & & $\dagger$ & \\
\hline ESR (log) & $0.176(0.087$ to 0.265$)$ & $<0.001$ & $0.178(0.088$ to 0.268$)$ & $<0.001$ \\
\hline BASDAI (square root) & $\dagger$ & & $\dagger$ & \\
\hline
\end{tabular}

†Not included in the model because the value did not show potentially significant association in univariate analysis $(p>0.1)$.

Methods: A total of 301 patients who have been treated with cDMARDs were enrolled from 1,280 patients in a single center cohort during 18 years of follow up. For each patient, time intervals of periods were created according to the prescription records. 'On-DMARD' intervals were time intervals of periods with SSZ or MTX treatment and 'off-DMARD' intervals were time intervals of periods without both SSZ and MTX treatment. The intervals were the periods excluding the treatment periods of TNF inhibitors. Radiographic progression was evaluated by the rate of Modified Stoke Ankylosing Spondylitis Spinal Score (mSASSS) change, an increase or decrease of mSASSS change per year. A generalized estimating equation models with adjustment for confounding covariates were used to evaluate the efficacy of cDMARDs on the radiographic progression.

Results: The number of 732 on-DMARD intervals and 1,027 off-DMARD intervals were obtained. Among the on-DMARD intervals, the proportion of intervals treated with SSZ (on-SSZ intervals), MTX (on-MTX intervals) and both of them (on-SSZ/MTX intervals) were $96.2 \%, 19.9 \%$ and $16.1 \%$, respectively. In the multivariable regression analysis, there was no significant decrease in the rate of mSASSS change during CDMARDs therapy $(\beta=-0.081, p=$ 0.418 ) (Table 1). And the mean rate of mSASSS change were 0.61 during on-DMARD intervals and 0.69 during off-DMARD intervals after adjustment of other covariates.

Conclusion: Treatment with cDMARDs in AS did not show significant impact in retarding spinal progression. In patients with $A S$, treatment with biologics rather than cDMARDs may be more effective in slowing radiographic progression. 